\title{
Ensino de História, memória e direitos humanos: reflexões sobre a transmissão da memória através do ensino de passados traumáticos
}

History Teaching, Memory and Human Rights: Reflections on the Transmission of Memory through the Teaching of Traumatic Past

Adrianna Cristina Lopes Setemy De Santis*

\section{RESUMO}

O texto apresenta reflexões acerca da relação entre educação, memória e direitos humanos, a fim de propor orientações pedagógicas e recomendações concretas para a abordagem de temas sensíveis do passado no ensino de História. A ideia é que, a partir de uma série de círculos concêntricos que permitam refletir sobre a experiência local, regional e nacional em direção à América Latina e ao mundo, se constitua uma base para lançar outros debates, outras perguntas e novas orientações diante dos desafios do tempo presente.

Palavras-chave: Educação; memória; direitos humanos.

\begin{abstract}
The text presents reflections on the relationship between education, memory and Human Rights, in order to propose pedagogical guidelines and concrete recommendations for addressing sensitive issues of the past in the teaching of History. The idea is that, based on a series of concentric circles that allow reflecting on the local, regional and national experience towards Latin America and the world, it becomes a basis for launching other debates, other questions and new orientations in the face of challenges of the present time.

Keywords: Education; memory; human rights.
\end{abstract}

Em meados de 2020, no momento em que estava elaborando as linhas iniciais deste texto a partir da pergunta "por que é importante falar em educação em direitos humanos no ensino e na aprendizagem de História?”, estátuas e monumentos de personagens associados à escravidão e ao colonialismo foram derrubados em diversas cidades dos Estados Unidos (EUA) e da Europa, por

\footnotetext{
* Universidade Salgado de Oliveira - UNIVERSO, Juiz de Fora, MG, Brasil. asetemy@gmail.com
} 
ativistas do movimento global Black Lives Matter, que ganhou força depois do assassinato brutal de George Floyd por um policial, em Mineapolis, nos EUA. Um dos primeiros alvos foi uma estátua de Cristóvão Colombo, decapitada em Boston. Na cidade inglesa de Bristol, a estátua do traficante de escravos Edward Colston foi derrubada e jogada no principal rio da cidade. Em Portugal, uma estátua do padre Antônio Vieira foi também destruída. As ações populares contra imagens que representam formas de dominação e colonização gerou grande controvérsia: afinal, o que fazer com as marcas de memória, como por exemplo as estátuas, que evocam a opressão e a dominação em pleno espaço público?

A história desses personagens nos convida a refletir sobre os perigos do racismo e da discriminação e suas estátuas podem servir como uma porta de entrada através da qual é possível trabalhar com estudantes, professores e a comunidade escolar como um todo a importância de promover o respeito pelos direitos humanos, diversidade cultural, princípios democráticos e liberdade. Essa proposta se enquadra em uma pedagogia da memória, ou seja, uma pedagogia que sabe que a memória é sempre um território de disputas, uma cena em movimento, e que cabe ao professor a responsabilidade de promover práticas que renovem a ideia de memória como um espaço dotado de vitalidade. Em consonância com os fundamentos pedagógicos da Base Nacional Comum Curricular (BNCC), essa proposta está de acordo com o conceito de educação integral, com o qual a BNCC está comprometida, e contribui para o desenvolvimento das competências gerais definidas como objetivo das 3 etapas da Educação Básica (Educação Infantil, Ensino Fundamental e Ensino Médio), uma vez que estimula ações que contribuem para a transformação da sociedade, tornando-a mais humana e socialmente justa (BNCC, 2018, p. 8).

Promover a discussão sobre os problemas relacionados à violência e discriminação, a partir das marcas de memória presentes no espaço público, permite que alunos de diferentes etapas da Educação Básica possam enfrentar os desafios da sociedade contemporânea e enxergar a realidade cotidiana em que estão inseridos com outros olhos, com outra sensibilidade e, assim, promover uma cultura de paz e a prevenção da violência (BNCC, 2018, p. 14). Por isso, de acordo com o compromisso com uma educação integral, torna-se cada vez mais necessário incorporar aos currículos e às propostas pedagógicas a abordagem de questões relacionadas à identidade e à construção de direitos, bem como pensar espaços para compartilhar essas reflexões produzidas no âmbito 
escolar com a sociedade civil de maneira mais ampla, a fim de assegurar uma formação humana integral para a construção de uma sociedade mais justa, democrática e inclusiva (BNCC, 2018, p. 14). As experiências compartilhadas com outros atores (colegas, professores, familiares) no ambiente escolar favorecerão, ao longo da Educação Básica, a construção da cidadania. Nesse sentido, é responsabilidade do professor de História, ao longo do Ensino Fundamental e Médio, oferecer práticas de ensino e aprendizagem com uma abordagem que esteja comprometida com direitos fundamentais, memória e identidade. Por isso é urgente que se discuta a noção de pedagogia da memória.

A seguir, apresentarei reflexões acerca da relação entre ensino de História, memória e direitos humanos, a fim de propor orientações pedagógicas e recomendações concretas para abordagem de temas sensíveis no ensino de História.

Na prática escolar, a construção de um conhecimento histórico comprometido com a educação em direitos humanos significa que o professor deve não apenas abastecer os alunos de informações e dados sobre os acontecimentos, fatos, personagens e processos relacionados a temas traumáticos, como escravidão, guerras, regimes fascistas e ditaduras, mas conduzir uma problematização que oriente os alunos no sentido de perceber a violência e as violações de direitos que caracterizam os fatos, acontecimentos e processos constitutivos de tais circunstâncias.

Essas ações têm por objetivo provocar nos alunos, a partir de uma série de círculos concêntricos que relacionam experiência local, regional e nacional em direção à América Latina e ao mundo, reflexões e sentimentos de compromisso com a democracia e defesa do Estado de Direito e dos direitos humanos. Nesse sentido, a abordagem de temas traumáticos deve constituir uma base para lançar outros debates, outras perguntas e novas orientações no tempo presente.

Através do que se pode denominar como pedagogia da memória (ROSEMBERG, 2010, p. 17), pretende-se contribuir para a formação de cidadãos críticos capazes de recordar e refletir sobre seus passados para pensar seus presentes e imaginar futuros mais justos, a partir de um processo de conhecimento em que o próprio aluno, orientado pelo professor, torna-se sujeito e se envolve no processo de construção social da memória sobre um passado que também será capaz de reconhecer como seu.

Refletir sobre a memória e os direitos humanos do campo educacional 
atual implica pensar em duas questões fundamentais. Por um lado, nos eventos traumáticos que marcaram o século XX em todo o mundo e, por outro, em como a memória e os direitos humanos se tornaram temas do ensino. Historicizar o surgimento dos direitos humanos ajuda a entender que eles foram o produto de construções e conquistas humanas e, nesse sentido, ainda há uma longa tarefa pela frente.

O movimento internacional pelos direitos humanos, em sua configuração contemporânea, tem uma história tão curta quanto a cultura atual que privilegia uma política da memória. Constelações políticas específicas do final do século XX, que resultaram do fim das ditaduras na América Latina, da queda do muro de Berlim, do colapso da URSS, do fim do Apartheid na África do sul e dos massacres da Bósnia e de Ruanda, resultaram tanto no desenvolvimento de uma cultura da memória e de discursos memoriais que apontam para a salvaguarda e valorização do passado, como também no desenvolvimento de movimentos de direitos humanos que apontam para a salvaguarda desses direitos no futuro.

Os movimentos sociais pelos direitos humanos têm suas origens nas denúncias de genocídios e violações de direitos fundamentais após esses eventos. É nesse momento que, segundo Huyssen, se estabelece uma relação intrínseca entre o discurso dos direitos humanos e o discurso da memória, afinal, pergunta o autor: "sem a memória dos campos de carnificina, onde estaria e que seria hoje os movimentos de direitos humanos?" (HUYSSEN, 2014, p. 199).

Ao longo da segunda metade do século XX, o Holocausto constituiu-se em referência para pensar sobre "passados traumáticos". Enzo Traverso, ao longo do texto "O totalitarismo: usos e abusos do conceito" (2005), argumenta que a memória do Holocausto, após ficar décadas reprimida e oculta, tornou-se o centro das representações do século XX. Logo após o término da Segunda Guerra Mundial, os relatos dos sobreviventes começaram a aparecer e chamar a atenção do grande público, como o diário de Anne Frank, inicialmente publicado na Holanda, em 1947, e o relato de Primo Levi, É isto um homem?, também publicado em 1947, na Itália. A despeito da literatura testemunhal, durante as duas primeiras décadas após o fim da Segunda Guerra, no campo historiográfico, muito se produziu a respeito dos conflitos e muito pouco se escreveu acerca do destino dos judeus europeus. A história que se produziu na França, na Inglaterra, nos EUA, era eminentemente uma "histó- 
ria dos vencedores", que destacava sobretudo o papel que os Estados Unidos e os demais países aliados tiveram na vitória contra o Eixo. A partir dos anos 1960, com o Julgamento de Eichmann, esse quadro historiográfico foi radicalmente modificado. Duas décadas após o fim da Segunda Guerra, as vozes dos sobreviventes passaram não apenas a ser ouvidas, como ganharam grande repercussão pública. Seus relatos ganhavam uma maior carga emotiva em meio a um "espetáculo testemunhal”, com ampla cobertura da imprensa, e na medida em que se reforçava a ideia de que o genocídio era um evento judaico e não um crime contra a humanidade.

Segundo Zygmunt Bauman na obra Modernidade e Holocausto, a partir daí o trauma do Holocausto levou grande parte dos historiadores e cientistas sociais a pensarem essa experiência em termos da sua singularidade dentro da história da humanidade e, nesse sentido, a memória do Holocausto foi se convertendo em "política da memória", presente na criação de memoriais, museus, datas comemorativas, literatura e filmes alusivos. Enquanto isso, a violência que caracterizou os processos de luta pela independência na Índia, Argélia, Moçambique e de consolidação de Estados como Indonésia, Uganda e Sudão raramente eram estudados e frequentemente não eram classificados como genocídios ou crimes contra a humanidade, mas caracterizados como uma espécie de anomalia periférica.

Esse quadro historiográfico mudou nos anos 1990, quando os eventos na Iugoslávia e Ruanda motivaram uma profusão de trabalhos sobre os crimes contra a humanidade e genocídios que caracterizaram os processos de emancipação política e os períodos pós-lutas de libertação na África e na Ásia. Esses estudos sobre os genocídios pós-coloniais somaram-se aos debates sobre o Holocausto, no sentido de compreender os crimes contra a humanidade. Muitos institutos universitários dedicados aos estudos do Holocausto foram renomeados para incluir a palavra genocídio ao lado de Holocausto, ampliando sua perspectiva de pesquisa. Longe de significar um abandono ou um enfraquecimento da historiografia do Holocausto, este novo enfoque produziu uma nova geração de historiadores e pesquisadores cujos trabalhos, segundo Andreas Huyssen, resultaram de encontros transnacionais de lembranças traumáticas (2014, p. 195-213). Huyssen chama atenção para o fato de que sempre houve um discurso da memória e que o discurso dos direitos, em si, tem uma história mais antiga. No entanto, o atual movimento internacional dos direitos huma- 
nos e os fluxos transnacionais da política da memória expressam, desde a década de 1990, uma conjuntura fundamentalmente nova.

Fato é que vivemos um tempo marcado pela proliferação de recordações, museus, comemorações e várias manifestações culturais sobre o passado. Segundo Elizabeth Jelin, vivemos em uma era de colecionistas. Há um culto que se expressa nos hábitos privados de guardar e registrar tudo (fotos de infância, recordações dos antepassados, coleções de diários e revistas). No espaço público, esse culto ao passado se expressa na crescente proliferação de arquivos públicos e privados, no aumento de datas comemorativas e demandas por monumentos e placas que organizam e marcam a presença do passado na vida contemporânea, e valorização das vozes sobreviventes do passado sob a forma de escritas biográficas, autobiográficas, diários íntimos, depoimentos, correspondências, blogs, relatos testemunhais e entrevistas (JELIN, 2002, p. 9). A essa invasão do espaço público por uma memória transformada em ritual e/ ou objeto de consumo, processo que Tzvetan Todorov denominou como "abusos da memória” (2002), não corresponde, contudo, a um compromisso com uma reflexão em torno dos traumas e violências que evoca.

Daí que se torna crucial para o desenvolvimento de práticas educativas em direitos humanos a questão sobre como investigar o passado a partir do presente: o que lembrar, como lembrar? Para o caso mais específico dos anos iniciais do Ensino Fundamental de crianças e jovens, coloca-se uma outra questão ainda mais delicada: como lembrar do que não se viveu, que não foi diretamente experimentado? Se o passado não foi vivido, só pode ser conhecido a partir de mediações que implicam na transmissão desse passado. $\mathrm{O}$ passado, inevitavelmente, pesa sobre nós, por ação, reação ou omissão, como um espectro que aponta para o bem e para o mal. O passado é sempre uma herança ou uma dívida, que será possível pagar ou não, descarregar ou guardar (DUSSEL, 2002, p. 272). Hassoun, no livro Los contrabandistas de la memoria (1997, p. 17) diz que a transmissão dá conta do passado e do presente, porque envolve ações e sentimentos atuais, além de definir os horizontes futuros. Nesse sentido, a pedagogia da memória se constitui no cotidiano escolar como o meio de transmissão de passados traumáticos através do trabalho de educadores que atuarão como portadores de conhecimentos específicos que possibilitarão a criação de vínculos significativos entre os alunos, suas próprias histórias, o passado ensinado, articulados à imaginação de um futuro desejado. 
Entretanto, é importante assinalar que transmissão não é sinônimo de reprodução da memória oficial ou compartilhada publicamente. E aqui cabe destacar um aspecto negativo da transnacionalização dos discursos de memória. Segundo Andreas Huyssen, esses encontros transnacionais de lembranças traumáticas levam, com frequência, a competições entre as memórias, segundo o modelo "meu povo sofreu mais que o seu". Isso porque a memória consiste em um campo de disputa política, como propôs Michael Pollak no texto "Memória, esquecimento, silêncio" (1989), onde chamou atenção para os processos de dominação e submissão das diferentes versões e memórias a respeito dos passados traumáticos. Apontando para a clivagem entre a memória oficial ou dominante e "memórias subterrâneas", marcadas pelo silêncio, pelo não dito, pelo ressentimento, o autor afirma que esta clivagem pode aparecer não apenas nas relações entre o Estado e a sociedade civil, como também entre a sociedade englobante e grupos minoritários. São lembranças "proibidas", "indizíveis", "vergonhosas" e muitas vezes "desmentidas", que frequentemente se opõem a formas mais poderosas e hegemônicas de memórias coletivas, tais como a memória nacional ou, ainda, uma memória que reafirma hegemonias e que, portanto, resulta no silenciamento e invisibilidade de memórias que incorporam experiências específicas.

Partindo da ideia de que os trabalhos da memória em torno dos acontecimentos traumáticos envolvem disputas de narrativas relacionadas a disputas políticas que dialogam com os interesses do presente, Andreas Huyssen afirma que o discurso dos direitos humanos, assim como as políticas de memória, deveriam ligar-se de maneira mais consistente às realidades específicas, como por exemplo, realidades regionais, locais, e de gênero, tanto em termos discursivos quanto práticos. Somente dessa forma, segundo o autor, será possível impedir que a memória, sobretudo a memória traumática, se torne um exercício vazio, que se alimenta de si mesmo, e que o discurso dos direitos humanos se torne uma abstração legalista em impecável harmonia com a democracia ocidental (HUYSSEN, 2014, p. 205-210).

Mas de que maneira está estruturada a transmissão da memória de passados traumáticos no ensino de História?

A produção de saberes históricos sobre passados traumáticos no cotidiano escolar tem sido uma das questões metodológicas mais debatidas nos cursos de licenciatura em História, mais especificamente na área do ensino de Histó- 
ria, onde vem sendo construído um consenso quanto ao papel assumido por alunos e professores no processo de ensino-aprendizagem: ambos são produtores de saberes, de culturas escolares. Ao professor de História cabe, portanto, assumir uma proposição investigativa nas aulas de História, o que implica em construir uma atitude reflexiva e questionadora diante do conhecimento historicamente produzido, sem se deixar cair no mero reprodutivismo que ainda predomina em muitas aulas de História. Essa proposição investigativa implica assumir uma concepção de conhecimento em que alunos e professores são sujeitos capazes de investigar e produzir saberes sobre suas próprias realidades históricas, estabelecendo relações críticas com o saber histórico construído no âmbito acadêmico e a "História oficial" veiculada, por exemplo, através das estátuas, museus e monumentos.

E quanto aos direitos humanos, de que maneira é possível despertar nos alunos, desde o ensino fundamental, a capacidade de refletir e reconhecer violações de direitos?

Na prática escolar, a construção de um conhecimento histórico comprometido com a Educação em direitos humanos, significa que o professor deve não apenas abastecer os alunos de informações e dados sobre os acontecimentos, fatos, personagens e processos, mas, sobretudo, instigá-los a uma problematização dos acontecimentos. Mais especificamente, quando se trata de catástrofes históricas, cabe aos professor orientar os alunos no sentido de perceber a violência e as violações de direitos humanos que caracterizam os fatos, acontecimentos e processos constitutivos de tais circunstâncias. O objetivo do processo é que, por meio do estudo das catástrofes e tragédias históricas, o aluno possa ser despertado e conscientizado dos valores relacionados à liberdade individual, a partir de um processo indutivo de conhecimento em que o próprio aluno, orientado pelo professor, torna-se sujeito do conhecimento e passa a se reconhecer como sujeito histórico e sujeito de direitos.

Nesse sentido, o estudo e transmissão de acontecimentos como o Holocausto e outras experiências de genocídio e políticas de perseguição e extermínio praticadas em diferentes épocas e partes do mundo podem ser transformados em uma "ponte" que interpela a própria experiência dos alunos.

O ensino do passado deve oferecer aos alunos de diferentes etapas da Educação a oportunidade de repararem que o mundo em que vivem nem sempre foi o mesmo, mas que, ao longo do tempo, passou por transformações, 
apesar das permanências. A tarefa do ensino de História é propor situações que permitam aos alunos avançar nessa construção, expandindo e enriquecendo suas ideias sobre os modos pelos quais o passado foi diferente do presente, em vários sentidos e dimensões.

Trabalhar com esses problemas na sala de aula pode contribuir para gerar um enredo que colabore com a construção de um relacionamento entre as novas gerações e o que aconteceu no passado, permitindo a construção de espaços propícios ao diálogo entre gerações. Ou seja, trata-se de construir uma relação de diálogo entre presente e passado, que não seja estática nem passiva. Segundo Hassoun, no processo de transmissão das memórias traumáticas, os silêncios consistem no que mais limita as novas gerações a processar e compartilhar essa herança, a fim de apropriarem-se efetivamente dela e recriá-la. No processo de reencontro com o passado e recriação das heranças recebidas, além do silêncio, o esquecimento também ocupa um lugar importante. A esse respeito, Hassoun afirma que reencontrar-se com o passado significa vincular-se com a herança recebida de maneira mais livre e menos atada àquilo que as gerações passadas não foram capazes de elaborar. Nas palavras do autor: "uma transmissão bem-sucedida oferece ao destinatário um espaço de liberdade e uma base que lhe permite abandonar (o passado) para melhor reencontrá-lo.” (HASSOUN, 1997, p. 17).

\section{COMO ENSINAR PASSADOS TRAUMÁTICOS? \\ UMA PEDAGOGIA DA MEMÓRIA PARA O ENSINO \\ DE HISTÓRIA E EDUCAÇÃO EM DIREITOS HUMANOS}

O ensino do passado, atravessado por eventos traumáticos, tem algumas especificidades que nos convidam a investigar como desenvolver uma "pedagogia da memória" que permita que o ensino da escravidão, do Holocausto ou das ditaduras no Brasil e na América Latina, para citar apenas alguns exemplos de genocídios e catástrofes históricas, produzam algum tipo de aprendizado significativo, no que diz respeito à valorização das liberdades fundamentais e da democracia.

A partir da reflexão preliminar sobre a relação intrínseca entre memória e direitos humanos, vimos que atualmente vivemos um tempo marcado pela proliferação de recordações, museus, comemorações e várias manifestações 
culturais sobre o passado, o que alguns autores, como Todorov, chamam de "abusos da memória". Isso porque, mesmo quando abundam as lembranças, os nomes de logradouros que lembram vítimas e acontecimentos traumáticos, os lançamentos de fascículos históricos, os documentários, as instalações artísticas, os monumentos, os museus e seus souvenirs, eles raramente conseguem dar vitalidade a um passado que aparece, acima de tudo, como um lastro, uma herança a ser carregada. Entretanto, trata-se de um lastro que refere-se a acontecimentos históricos que produziram fraturas, feridas difíceis de serem fechadas, e desarticularam os laços sociais mais elementares da vida coletiva.

Nesse sentido, o ensino desses acontecimentos coloca à educação e, mais especificamente, ao professor de História o desafio de formular algumas perguntas fundamentais: como ensinar o indizível, o ininteligível? Como convocar, trazer à tona, o passado traumático sem que se torne um fardo difícil de carregar? Como se reconectar com esses passados no contexto de uma "epidemia da memória”, transformada em objeto de consumo (HUYSSEN, 2000, p. 18)? O que dizer e como refletir sobre condutas violadoras dos direitos humanos? Para que e por quê? Através de quais recursos e estratégias? Devemos recuperar o passado como um texto completo, progressivo e linear ou aceitar que ele chegará até nós com intermitências, a partir das brumas e fragmentos da memória? Como interrogar esses passados a partir do presente?

Através de museus, monumentos, fotografias, filmes de ficção, documentários, vídeos e programas de televisão, o passado traumático retorna e se instala no presente. Essa mesma observação vale também para os monumentos, museus e estátuas que foram erguidos ou preservados no espaço público em homenagem a exploradores, colonizadores que dominaram povos fazendo uso da violência, como nos exemplos mencionados no início deste artigo. Na obra La restauración nacionalista, publicada na primeira década do século XX, o escritor argentino Ricardo Rojas, depois de ter passado uma temporada na Europa com o objetivo de estudar os sistemas educativos, sobretudo o ensino de História, afirmou que aquele era o momento dos nacionalismos e do fortalecimento das identidades nacionais, em detrimento das memórias universais. No último capítulo, intitulado "Bases para un renacimiento nacionalista", Ricardo Rojas afirma que seria impossível ensinar e aprender a história nacional sem imagens que, distribuídas através do espaço público na forma de estátuas, monumentos e memoriais, condensassem os acontecimentos e perso- 
nagens mais destacados do passado. Em seu plano pedagógico para a restauração nacionalista por meio da História, Rojas propôs que fossem erguidas estátuas e monumentos que recordassem os próceres da nação argentina e afirmou a existência do que denominou como uma "pedagogia das estátuas":

a história não se ensina apenas na sala de aula: $o$ sentido histórico, sem o qual a história é estéril, se forma no espetáculo do cotidiano, na nomenclatura tradicional dos lugares, nos lugares associados às memórias heróicas, nos restos dos museus, e mesmo em monumentos comemorativos, cuja influência sobre a imaginação chamei de pedagogia das estátuas. Mas esses são elementos didáticos estranhos à escola, embora todo governo esclarecido deva também utilizá-los na formação da nacionalidade. Dentro da sala de aula, o professor vai aproveitá-los com frequência, mas de acordo com o plano imposto pelo Estado. (ROJAS, 2011, p. 221, tradução nossa)

Embora as concepções de ensino de História tenham sofrido profundas transformações ao longo do século XX, ainda hoje entende-se que esses espaços e imagens fazem parte do processo de construção de histórias e identidades, ajudam a moldar e dar sentido aos relatos e representações sobre o passado, evocam e transmitem às novas gerações memórias relacionadas aos acontecimentos de um passado compartilhado. Entretanto, ao longo do século XX, os monumentos tradicionais, como forma de recordar o passado, tornaram-se alvo de críticas severas, a medida em que foram se tornando cada vez mais obsoletos os paradigma nacionais de memória que remontam ao que Halbwachs denominava como "memória coletiva". A crítica à monumentalização do passado a partir de uma perspectiva oficial do Estado acompanhou o processo de proliferação de memórias característico da contemporaneidade, como foi mencionado nos parágrafos anteriores. Assim, a partir de meados dos anos 1990, a explosão de uma "cultura da memória" que ultrapassa os domínios narrativos do Estado e incorpora diversas demandas de comemoração passou a competir por um lugar no espaço público e se articulou de maneira vigorosa na literatura, nas artes plásticas, em filmes e documentários e até na arquitetura de museus e memoriais.

A invasão do espaço público por uma arte marcada pela centralidade das memórias traumáticas, muitas vezes transformada em ritual e/ou objeto de consumo, resulta do fenômeno "industrialização da memória" (HUYSSEN, 
2002). Huyssen afirma que essa "cultura da memória" característica da contemporaneidade seria em parte uma resposta às mudanças rápidas e a uma vida sem raízes. Nesse sentido, a "cultura da memória", presente no espaço público de forma cada vez mais pulverizada, comercializada e veiculada pelos meios de comunicação de massa, tem um papel significativo como mecanismo cultural para fortalecer a identidade e o sentido de pertencimento a grupos ou comunidades (HUYSSEN, 2000).

Apesar de todas essas mudanças epistemológicas mencionadas no parágrafo anterior, os memoriais mantêm, ainda hoje, uma relação ambígua com o espaço público e com a produção do conhecimento histórico. Isso porque mesmo os memoriais que fazem referência aos traumas históricos são construídos e protegidos pelas mesmas leis patrimoniais que salvaguardam os memoriais tradicionais e são construídos com o mesmo objetivo de integrar narrativas identitárias. Adrián Gorelik, pensando a respeito da permanência dessa ambiguidade entre memoriais que evocam vítimas (em detrimento dos heróis) e espaço público, propõe que se reescreva o conceito de "pedagogia das estátuas” proposto por Ricardo Rojas, no sentido de ampliá-lo pela integração desses produtos da "indústria da memória" aos monumentos tradicionais. Contudo, não se pode perder de vista que o conceito proposto por Rojas era a pedagogia do "civismo, da estética e da história", visando restauração nacionalista por meio da História (ROJAS, 2011, p. 271).

Contudo, dos registros do trauma em espaços públicos e imagens espera-se que estejam orientados em direção ao futuro e que não se limitem a uma simples reiteração do passado. Devem ter um sentido político, dinâmico, e não apenas um caráter nostálgico. Portanto, em lugar de uma "pedagogia das estátuas”, programa pedagógico marcado por um tom nostálgico e orientado em direção ao passado, proponho uma "pedagogia da memória”, plano pedagógico para garantia dos direitos humanos, no presente e no futuro, por meio do ensino de História. Falar em "pedagogia da memória" implica refletir sobre o problema da transmissão geracional, o problema da representação e o problema da dimensão espacial (ROSEMBERG, 2010, p. 17-23).

Em 1940, no texto “Teses sobre o conceito da história”, Walter Benjamin afirmou que "existe um encontro secreto, marcado entre as gerações precedentes e a nossa" (BENJAMIN, 1994, p. 223). Embora o encontro entre as gerações pudesse ocorrer, era "secreto": ninguém sabe quando ou onde pode 
ocorrer. Considerando que uma das características do mundo contemporâneo é a dificuldade de estabelecer o vínculo geracional, ${ }^{1}$ condição necessária para qualquer situação de transmissão, como os espaços e imagens produzidos com o objetivo de relembrar o passado traumático podem ser usados no sentido de concretizar o encontro entre aqueles que viveram as experiências traumáticas do passado e os que nasceram em um mundo completamente diferente? Como o ensino de História pode servir à concretização desse encontro entre aqueles que viveram as experiências traumáticas do passado e os nascidos em um mundo completamente diferente? O ensino de História, enquanto instrumento e veículo de transmissão de um legado entre uma geração e outra, continua tendo esse desafio no centro de suas preocupações.

O ensino do passado nas aulas de História deve ser orientado no sentido da concretização desse encontro, para que os jovens, a partir de suas próprias vivências, apropriem-se das experiências traumáticas do passado. A concretização desse encontro entre gerações, através do processo de ensino e aprendizagem da história do passado pode ser também denominado de conformação de "consciência histórica".

No ato da transmissão estão em jogo as condições reais de recepção do passado no presente, que podem ser marcadas por imaginários geracionais, regionais e de classe, que disputam entre si o significado atribuído ao que recebem. Uma educação em direitos humanos no ensino e aprendizagem de História deve considerar que os alunos trazem consigo motivações, contextos familiares, pessoais e sociais muito diferentes, que irão orientar os vínculos que constroem com o passado.

Essas disputas de representações do passado devem ser convertidas pelo professor não em um problema ou constrangimento, mas no próprio motor da reflexão pedagógica e política em sala de aula. Por exemplo, isso pode se aplicar a uma situação, infelizmente cada vez mais comum, em que alunos trazem para a sala de aula a fala de pais que negam a existência das ditaduras, regimes fascistas ou mesmo da escravidão. Uma situação como essa pode ser instrumentalizada pelo professor de História em sala de aula, como espaço propício ao estabelecimento de um diálogo geracional orientado no sentido da defesa das liberdades fundamentais e dos direitos humanos.

Considerando que o ponto de partida de toda aula de História, assim como da pesquisa histórica, deve ser a proposição de um problema, o docu- 
mento histórico (de variadas naturezas) se apresenta como o lugar do problema a ser proposto pelo professor. Afirmações do senso comum, como por exemplo "bom era no tempo dos militares" ou "não me lembro de ter havido ditadura militar", "os campos de concentração não existiram" ou ainda "a escravidão foi benéfica para os negros", podem ser tomadas como documentos históricos e tornarem-se objeto de crítica histórica, a partir da qual é possível estabelecer o gancho para utilizar outros documentos, como notícias de jornais da atualidade sobre grupos de pessoas que pedem "intervenção militar" ou defendem redução de cotas para negros por não reconhecerem a dívida histórica do país com descendentes de negros escravizados, depoimentos e também documentos de arquivo produzidos em diferentes épocas e que hoje podem ser constituídos enquanto evidência das violências e violações do passado. $\mathrm{O}$ objetivo do trabalho de contraposição entre falas do senso comum e fontes históricas de diferentes naturezas deve ser a construção de conceitos, por meio dos quais o aluno possa produzir sua leitura do mundo. Esses conceitos, relacionados sobretudo ao que se entende por direitos humanos e liberdades fundamentais, devem ser historicizados, e não absolutizados, cabendo ao professor de História a tarefa de chamar atenção para a mudança operada em determinados conceitos ao longo do tempo. Ao final do processo, o professor terá conduzido o aluno na construção do seu objeto de conhecimento e promovido o seu desenvolvimento como sujeito histórico, sujeito da investigação e sujeito de direitos. Dessa forma, terá ultrapassado a simples reprodução de conhecimentos estabelecidos, que agora adquirem um novo sentido: o que interessa não é mais a simples compreensão ou memorização dos conteúdos históricos, mas a sua interrogação tendo em vista o objetivo educacional da construção da noção de direitos humanos.

Para além da questão da transmissão geracional, a construção de um conhecimento histórico comprometido com a Educação em direitos humanos deve considerar o problema da dimensão espacial. A questão que se coloca é: como propor uma "pedagogia da memória" que leve em consideração a construção coletiva de memórias locais inscritas em uma memória mais ampla, de dimensões transnacionais, e em permanente construção? Poderíamos dizer que, para gerar uma aprendizagem significativa, essa dimensão é fundamental e pode ser problematizada a partir de perguntais como: "por que isso aconteceu na minha localidade?” ou "por que isso não aconteceu?”. É necessário contrabalançar as narra- 
tivas históricas e memorialísticas dominantes, que muitas vezes têm como palco os espaços das grandes cidades, com as realidades mais próximas da vida dos estudantes (locais, regionais). Considerar essa dimensão espacial significa lançar as bases para uma nova compreensão do passado que evidencia os diferentes impactos dos eventos e fenômenos da história em diferentes realidades sociais.

Mas quais representações os professores de História devem escolher para a tarefa de ensinar sobre os traumas do passado e torná-los inteligíveis para diferentes gerações em espaços distintos? Imagens ou relatos testemunhais que representam horror de maneira simbólica? Imagens/falas reais ou fictícias? Quais são os limites éticos e estéticos da representação de passados tão dolorosos?

Essas perguntas contêm uma contradição que evidencia o campo de tensões que atravessa a possibilidade de representar e ensinar passados dolorosos, experiências limite, carregadas de sofrimento, e parecem abrir mais perguntas do que oferecer respostas, mostrando que a contradição ou paradoxo de "representar o irrepresentável” se sustenta, entre outras coisas, na sensação, ancorada em um limite moral, de que o horror que nos é representado não deveria ter ocorrido. Por trás dessas perguntas está uma questão central para o processo de ensino e aprendizagem de História: que fontes históricas devemos disponibilizar para os nossos alunos tendo em vista a construção de conhecimento a partir da pesquisa histórica em sala de aula? Com que objetivo?

No ensaio "Diante da dor dos outros", Susan Sontag (2003) afirma que as obras de arte têm a capacidade de treinar nossa imaginação para reconhecer "a dor alheia", as violações de direitos a que o outro é submetido. Nesse sentido, o registro dos acontecimentos traumáticos em espaços públicos e imagens pode ser entendido como parte de um esforço em garantir a concretização desse encontro entre gerações, além do direito à verdade, memória e justiça das vítimas de graves violações de direitos humanos e seus descendentes.

Inicialmente, podem-se distinguir dois tipos de representações do trauma:

1. Representações que guardam um vínculo material direto com os acontecimentos como, por exemplo, os escombros do muro de Berlim, os escombros das torres gêmeas, ambos transformados em memoriais; os óculos de Allende, memoriais situados em antigos campos de concentração, como Dachau e Auschwitz; o documentário A tristeza e a piedade, crônica de uma cidade francesa sob a Ocupação Clermont-Ferrand, a 387 quilômetros de Paris e a 59 quilômetros de Vichy, entre 1940 e 194 (trata-se da montagem de fragmentos de 
cinejornais e depoimentos de gente da cidade e de políticos, militares alemães, ingleses e integrantes da Resistência Francesa, simpatizantes e colaboracionistas); o Estádio Nacional do Chile, o Espaço de Memória Londres 38, em Santiago (Chile); túnel Zuzu Angel, no Rio de Janeiro (Brasil); Memorial da Resistência, em São Paulo (Brasil); Museu da Memória, em Rosário (Argentina).

2. Representações que resultaram, posteriormente aos fatos históricos, da iniciativa e do trabalho de instituições, grupos e autoridades como, por exemplo, o Parque da Memória (Buenos Aires); o LUM (Lugar de Memória, Tolerância e Inclusão Social, no Peru); Museu da Memória e dos Direitos Humanos, em Santiago (Chile); Museu da Memória, de Ayacucho (Peru); Museu da Memória (MUME), em Montevidéu; os memoriais do Holocausto espalhados por diferentes partes do mundo, como nos EUA e no Brasil (em Curitiba); o recém criado Memorial Nacional pela Paz e pela Justiça, em Montgomery (EUA), dedicado a recordar todas as pessoas negras que sofreram algum tipo de violência ao longo da história.

Apesar de distintas quanto à natureza, essas representações têm em comum o propósito pelo qual devem ser criadas ou já foram criadas: colocar na esfera pública de maneira destacada um dispositivo que permita evocar as experiências das vítimas de violações de direitos humanos para além do tempo que seus familiares ou outros promotores da homenagem possam assegurar o exercício dessas memórias. Os exercícios de memória a partir de fatos traumáticos do passado compartilhados entre gerações através imagens e espaços públicos deve visar não apenas a imposição de uma versão, mas a construção de espaços propícios ao diálogo a partir da defesa de direitos fundamentais e dos direitos humanos.

Nesse sentido, entendo que o movimento de derrubada de monumentos que representam formas de dominação e colonização em meio a chamada “obsessão comemorativa" ou "epidemia de memórias", é uma evidência de que as contas com o passado não estão saldadas, nem em termos institucionais nem em termos simbólicos, e tornaram-se questões públicas inevitáveis e incontornáveis. A proposta de Huyssen parece oferecer uma resposta à controvérsia em torno da derrubada desses monumentos: o discurso dos direitos humanos e as políticas de memória devem ligar-se de maneira mais consistente em torno dos usos e sentidos que são atribuídos a essas imagens e espaços públicos, no presente (2014, p. 205-210). Nesse sentido, derrubar, decapitar e afogar monumentos pode significar o esvaziamento do espaço público dos conflitos que caracte- 
rizam os trabalhos que são próprios da memória. Afinal, "é a partir do que vemos hoje que julgamos e compreendemos o passado." (BRAUDEL, 1988, p. 4)

Colocar em prática no ensino e aprendizagem de História uma "pedagogia da memória" significa incluir o problema dos direitos humanos na atualidade a partir do princípio de que esses direitos não nos são concedidos de modo definitivo, mas são o produto de lutas coletivas permanentes. $\mathrm{O}$ reconhecimento dessa dimensão é fundamental no sentido de transmitir aos alunos de diferentes etapas do Ensino Fundamental e Médio a ideia de que a luta por liberdades fundamentais não ficou para trás. Exige responsabilidade e participação no presente. Ou seja: se os direitos humanos existentes surgiram a partir do reconhecimento das lutas de homens e mulheres, sua expansão e cumprimento dependerão da responsabilidade de cada um de nós no presente.

A Educação em direitos humanos no ensino História deve ser considerada como objetivo fundamental para a construção de um mundo justo, habitada por cidadãos ativos cuja responsabilidade em relação aos outros surge, entre outras coisas, ao reconhecer-se como parte de um passado comum que não requer ser adorado e reverenciado, como propunha a "pedagogia das estátuas", mas reinventado no presente, como propõe a "pedagogia da memória”.

\section{REFERÊNCIAS}

BAUMAN, Zygmunt. Modernidade e holocausto. Rio de Janeiro: Zahar, 1998.

BENJAMIN, Walter. Sobre o conceito da história. In: Magia e técnica, arte e política: ensaios sobre literatura e história da cultura. Tradução de Sérgio Paulo Rouanet. 7.ed. São Paulo: Brasiliense, 1994, p. 222-232

BRASIL. Base Nacional Curricular Comum. Brasília: Ministério da Educação, 2018.

BRAUDEL, Fernand. O espaço e a História no Mediterrâneo. Martins Fontes, 1988.

CARRETERO, Mario (Org.). Enseñanza de la historia y memoria colectiva. Buenos Aires: Paidós, 2006.

DUSSEL, Inés. La educación y la memoria. Notas sobre la política de la transmisión. Anclajes 6.6 (2002), p. 267-293.

HASSOUN, Jacques. Los contrabandistas de la memoria. Ediciones de la Flor, 1996.

HUYSSEN, Andreas. En busca del futuro perdido: cultura y memoria en tiempos de globalización. Fondo de cultura económica, 2002.

HUYSSEN, Andreas. Os direitos humanos internacionais e a política da memória: limi- 
tes e desafios. In: HUYSSEN, Andreas. Culturas do passado-presente: modernismo, artes visuais, políticas da memória. Rio de Janeiro: Contraponto, 2014, p. 195-213.

HUYSSEN, Andreas. Seduzidos pela memória: arquitetura, monumento, mídia. Rio de Janeiro: Aeroplano, 2000.

JELIN, Elizabeth. Los trabajos de la memoria. Siglo XXI de España, 2002.

POLLAK, Michael. Memória, esquecimento e silêncio. In: Estudos Históricos, 1989, v. 3, p. 3-15.

REBAGLIATI, María. Infancias, sujetos y familias en la Educación Inicial. Buenos Aires: Ministerio de Educación de la Nación, 2010. Disponível em: http://repositorio. educacion.gov.ar:8080/dspace/handle/123456789/109584. Acesso em: $10 \mathrm{dez}$ 2019.

ROJAS, Ricardo. La restauración nacionalista: informe sobre educación. Buenos Aires: UNIPE, 2011.

ROSEMBERG, Julia. Educación, Memoria y Derechos Humanos: orientaciones pedagógicas y recomendaciones para su enseñanza. Buenos Aires: Ministerio de Educación de la Nación, 2010.

RÜSEN, Jörn. Didática da História: passado, presente e perspectivas a partir do caso alemão. In: SCHMIDT, Maria Auxiliadora; BARCA, Isabel; MARTINS, Estevão de Rezende (Orgs.). Jörn Rüsen e o ensino de história. Curitiba: Editora UFPR, 2010, p. 23-40.

SONTAG, Susan. Diante da dor dos outros. São Paulo: Companhia das Letras, 2003.

TODOROV, Tzvetan. Los abusos de la memoria. Buenos Aires: Paidós, 2009.

TRAVERSO, Enzo. El totalitarismo: usos y abusos de un concepto. In: Las escalas del pasado: IV Congreso de Historia Local de Aragón (Barbastro, 3-5 de julio de 2003). Instituto de Estudios Altoaragoneses, 2005, p. 99-110.

\section{NOTAS}

${ }^{1}$ Possíveis explicações para essa dificuldade de estabelecimento de vínculos geracionais são: mudanças tecnológicas e transformações culturais; lacunas sociais e econômicas que se abriram com a crescente globalização; valorização simbólica da "juventude"; a perda do valor vital do passado frente a um "excesso de presente", produzidos pelos meios de comunicação de massa, coloca a sociedade em um presente permanente e dificulta a possibilidade de diálogo entre o passado e o presente, ou seja, entre jovens e adultos.

Artigo submetido em 6 de novembro de 2020. Aprovado em 28 de janeiro de 2021. 